\title{
A formação em medicina de família no Brasil: a necessidade de caminhos convergentes
}

\author{
The training in family medicine in Brazil: the necessity of converging paths
}

\section{La formación en medicina familiar en Brasil: la necesidad de caminos convergentes}

Nesta primeira edição de 2014, a RBMFC discute o tema da educação médica que também reflete na formação do médico de família e comunidade. Assim, ao longo deste ano, a RBMFC publicará artigos sobre experiências nacionais e internacionais voltadas à formação de médicos para a APS. Esta iniciativa visa dialogar com o atual contexto brasileiro em que a especialidade de Medicina de Família e Comunidade (MFC) vivencia grande expansão, devido aos incentivos oferecidos pelo governo federal para a ampliação de residências médicas em áreas estratégicas do SUS.

O crescimento nacional dos programas de residência em MFC (PRMFC) para 2014 é da ordem de 287 novas vagas, distribuídas nos diversos entes federados. ${ }^{1}$ Municípios que optaram por ampliar suas vagas em MFC, como São Paulo (44 vagas), Rio de Janeiro (40 vagas), Curitiba (20 vagas), Palmas (20 vagas), Florianópolis (16 vagas), Itajubá (10 vagas), Salvador (10 vagas) e Recife (8 vagas), demonstram como a especialidade cresceu, devido a política de financiamento para áreas médicas prioritárias do SUS.

Esse contexto cria desafios, tanto para os governos e a Comissão Nacional de Residência Médica (CNRM) como para a Sociedade Brasileira de Medicina de Família e Comunidade (SBMFC), na garantia da qualidade desses programas, visto que estes requerem treinamento de tutores/preceptores e padronização de conteúdos centrais da especialidade. Se adicionarmos a esse cenário a meta governamental de implantar progressivamente, até 31 de dezembro de $2018,{ }^{2}$ a obrigatoriedade de que todo recém-graduado em medicina deva passar primeiro por um ano de residência em MFC (para depois, caso deseje, se candidatar a outra especialidade), a necessidade de novos espaços formativos em MFC será muito maior.

Diante desse cenário crescente de implantação de novos programas de treinamento em MFC, esta edição traz dois artigos que ilustram a formação de médicos na Inglaterra, de modo a contribuir para essa questão, visto que o Reino Unido possui uma população culturalmente diversa, estimada em aproximadamente 63,7 milhôes de habitantes, ${ }^{3}$ e conta com cobertura universal de saúde por meio do National Health Service, ou simplesmente NHS, de reconhecida importância e historicidade enquanto Sistema Nacional de Saúde público, universal e com APS forte e efetiva.

$\mathrm{Na}$ Inglaterra a formação em medicina ocorre em três fases: graduação, programa de fundação (Foundation Programme) e especialização (Special Training). Cada uma dessas fases conta com requerimentos de entrada ou exames específicos, que em certa medida organizam a absorção de médicos estrangeiros ao longo dessas diferentes fases. Essas fases também contribuem para organizar o debate em torno da terminalidade do curso de medicina.

O curso de medicina, para os britânicos, não habilita o recém-graduado a exercer a profissão médica. Contudo, ele confere aos graduados plenos direitos de seguirem outros caminhos na carreira, como pesquisadores ou acadêmicos, em áreas outras que não envolvam a assistência direta de pacientes. A função principal da graduação em medicina é fornecer a base necessária para as fases profissionalizantes e remuneradas, por exemplo, o Foundation Programme $e^{4}$ no qual os jovens médicos passam dois anos, de modo a auxiliá-los na escolha de suas carreiras profissionais e especialidades. 
Trata-se, portanto, de um verdadeiro rito de passagem da graduação universitária para a fase de imersão gradual nos serviços do NHS, por meio do programa de fundação e depois pela especialização. Esse cuidado todo visa expor o jovem médico às responsabilidades crescentes de situaçôes clínicas, mas também reflete alto grau de segurança e consequente qualidade estabelecida pelo NHS. A universidade tem papel importante na primeira fase, porém esta passa a ter um papel complementar no programa de fundação, passando os órgãos de classe a serem os responsáveis (i.e. no caso dos médicos de família, o Royal College of General Practitioners - RCGP) $)^{5}$ pela qualidade da formação profissional médica especializada para a APS, em parceria com as instituiçôes formadoras do NHS, atualmente denominadas Health Education England (HEE), ${ }^{6}$ distribuídas em diversas regionais no país.

O HEE é responsável pelo planejamento e desenvolvimento de toda a força de trabalho em saúde, apoiando e autorizando o desenvolvimento dos Local Education and Training Boards (Conselhos de treinamento e educação locais e/ou regionais), de modo a promover uma educação e formação de alta qualidade, que responda às necessidades de pacientes e comunidades, em concordância com padróes estabelecidos pelos órgãos reguladores. No caso da medicina de família, este padrão está sob a responsabilidade do RCGP, que estabelece os conteúdos do programa de treinamento a serem adotados nacionalmente por todos os centros formadores, bem como, os exames nacionais (Applied Knowledge Test [AKT] e Communication Skill Assessment - CSA), e o e-portfólio (vinculado à plataforma do RCGP) ao qual todos os GP em treinamento devem estar registrados, a fim de demostrarem que estão atendendo aos requisitos estabelecidos pelo RCGP. É por meio do e-portfólio que os preceptores - que fazem o acompanhamento nos locais de treinamento - registram os comentários e anotações referentes à progressão dos médicos residentes.

Diante dos desafios que o Brasil tem em formar profissionais médicos para a APS/ESF, em grande escala e em curto prazo, uma estratégia possível seria o fortalecimento da SBMFC como instituição parceira junto aos Ministérios da Saúde e da Educação, uma vez que a SBMFC (enquanto associada da AMB) possui acúmulo prático e teórico na formação em MFC, bem como, vem aplicando desde 2004 exames regulares para a titulação de médicos de família em todo o Brasil, por meio do TEMFC. Esta parceria favoreceria a criação de instrumentos em certa medida semelhantes ou análogos aos adotados pelos britânicos, tais como: construção de currículo comum; organização de e-portfólio (podendo ser associado às matrizes de ensino a distância como Telessaúde e Telemedicina); e realização de exames nacionais de conclusão de curso descentralizados (semelhantes ao TEMFC), constituindo assim, estratégia inovadora para assegurar o padrão requerido para uma formação em MFC de qualidade, em nível nacional.

A experiência britânica aponta um caminho convergente, pois desde o surgimento do NHS, governos e respectivos órgãos de classe, necessitaram apoio mútuo. Sendo assim, no Brasil, para se atingir a universalização do SUS, o Ministério da Saúde e a SBMFC necessitam ser parceiros neste desafio, pois sem uma Medicina de Família forte não há APS forte. ${ }^{7}$

\section{Referências}

1. Ministério da Saúde (BR), Secretaria de Gestão do Trabalho e da Educação na Saúde; Ministério da Educação (BR), Secretaria de Educação Superior. Portaria conjunta no 12, de 20 de dezembro de 2013. Brasília: Diário Oficial da União. 2013 Dez 23; Seção 1:141-51. Available from: http://pesquisa. in.gov.br/imprensa/jsp/visualiza/index.jsp?data=23/12/2013\&jornal=1\&pagina=141\&totalArquivos=220

2. Brasil. Lei $n^{\circ}$ 12.871, de 22 de outubro de 2013. Institui o Programa Mais Médicos, altera as Leis $n^{\circ} 8.745$, de 9 de dezembro de 1993, e $n^{\circ}$ 6.932, de 7 de julho de 1981, e dá outras providências. Brasília: Portal da Legislação; 2013 Out 22. Available from: http://www.planalto.gov.br/ ccivil_03/_ato2011-2014/2013/Lei/L12871.htm

3. Office for National Statistics. [Internet]. UK: ONS; [update 2013 Aug 8; cited 2014 Jan 12]. Population. Available from: http://www.ons.gov.uk/ons/ taxonomy/index.html?nscl=Population

4. Foundation Programme [Internet]. UK: UKFPO; c2014 [cited 2014 Jan 12]. Available from: http://www.foundationprogramme.nhs.uk/pages/home

5. Royal College of General Practitioners [Internet]. Londres: RCGP; c2014 [cited 2014 Jan 18]. Available from: http://www.rcgp.org.uk

6. NHS Health Education England [Internet]. UK: NHS; c2014 [cited 2014 Jan 18]. Available from: http://hee.nhs.uk

7. Gérvas J. Atención Primaria fuerte es aquella que dispone de instrumentos que le permiten medir la calidad que ofrece (para su continuo mejoramiento). Rev Bras Med Fam Comunidade. 2013;8(29):223-4. Available from: http://dx.doi.org/10.5712/rbmfc8(29)834 